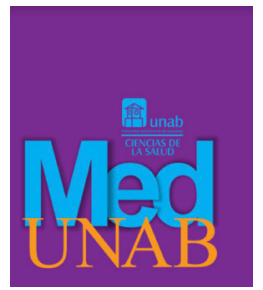

REVISTA DE LA FACULTAD

DE CIENCIAS DE LA SALUD

\title{
Queratitis herpética atípica multifocal secundaria a corticoides tópicos
}

Multifocal atypical herpetic keratitis secondary to topical corticosteroids

Ceratite herpética multifocal atípica secundária a corticoides tópicos

Virgilio Galvis, MD., Esp., PhD. ${ }^{1}$, Alejandro Tello, MD., Esp., PhD. ${ }^{1}$ (D) Lisi Rodríguez, MD. ${ }^{2}$, Lizeth Ardila, MD. ${ }^{3}$, Angelica Pedraza-Concha, MD. ${ }^{4}$ (D), Camilo Niño, MD., Esp. ${ }^{5}$

1. Médico, Especialista en Oftalmología, Subespecialista en Facoemulsificación y Segmento Anterior, Subespecialista en Cirugía refractiva, Doctorado en Investigación, Cirugía y especialidades Médicoquirúrgicas, Doctorado en Ciencias de la Visión, Centro Oftalmológico Virgilio Galvis, Universidad Autónoma de Bucaramanga, Fundación Oftalmológica de Santander, Floridablanca, Santander, Colombia.

2. Médico, Universidad Autónoma de Bucaramanga, Floridablanca, Santander, Colombia

3. Médico, Médico de Bienestar Universitario, Universidad Autónoma de Bucaramanga, Bucaramanga, Santander, Colombia

4. Médico, en Servicio Social Obligatorio, Asistente Editorial, Universidad Autónoma de Bucaramanga, Floridablanca, Santander, Colombia

5. Médico, Especialista en Oftalmología, Subespecialista en Córnea y Segmento Anterior. Centro oftalmológico Virgilio Galvis, Fundación Oftalmológica de Santander, Universidad Autónoma de Bucaramanga, Floridablanca, Santander, Colombia.

Correspondencia: Angélica Pedraza Concha, Calle 157 No. 14 - 55, Floridablanca, Santander, Colombia. E-mail: apedraza72@unab.edu.co

Cómo citar: Galvis V, Tello A, Rodríguez L, Ardila L, Pedraza-Concha A, Niño C. Queratitis herpética atípica multifocal secundaria a corticoides tópicos. MedUNAB. 2019;22(1):12-15. doi: 10.29375/01237047.3637

\section{INFORMACIÓN ARTÍCULO}

Artículo recibido: 25 de mayo de 2019

Artículo aceptado: 10 de julio de 2019

DOI: https://doi.org/10.29375/01237047.3637 

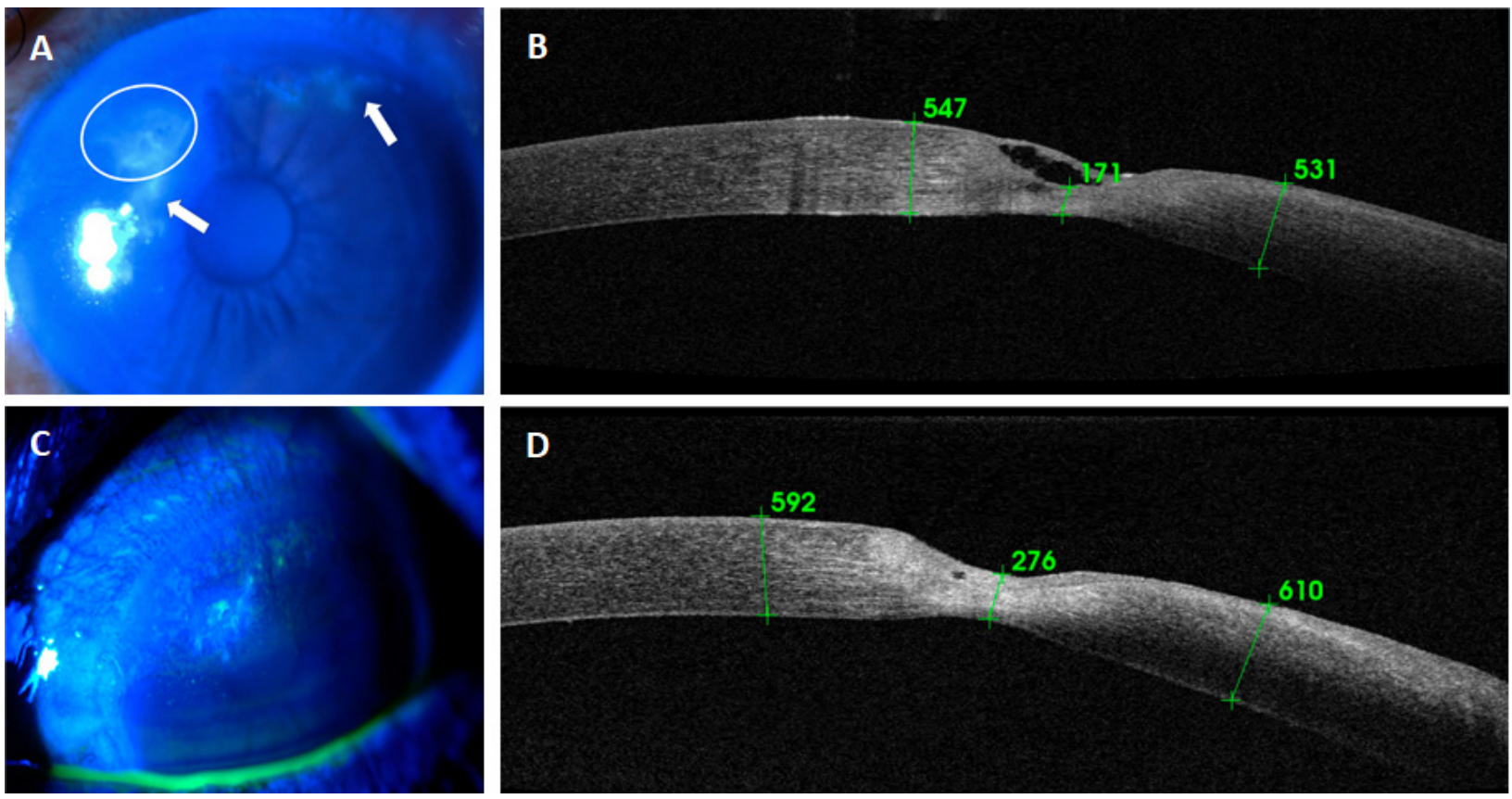

Figura A. OI: fotografía en lámpara de hendidura con filtro de azul de cobalto. La tinción con fluoresceína permite apreciar dos úlceras separadas de aspecto dendrítico (flechas blancas) que comprometen la media periferia, tanto superonasal (meridiano de las 9 y 10:30 horas), como superior (meridiano de las 12 y las 2 horas). Adicionalmente, lesión ulcerativa con compromiso estromal de aproximadamente de $3 \times 2 \mathrm{~mm}$ con adelgazamiento de más del $50 \%$ del espesor corneal (óvalo blanco). Figura B. OI: tomografía de coherencia óptica de la córnea. Se observa área de adelgazamiento (remanente estromal respetado de $171 \mu \mathrm{m}$ ) con quiste epitelial sobre el área de ulceración estromal. Figura C. OI: fotografía en lámpara de hendidura con filtro de azul de cobalto. La tinción de fluoresceína permite apreciar solo mínima captación del colorante sobre las áreas de las úlceras dendríticas epiteliales, así como cicatrización casi completa de la ulceración estromal. Figura D. OI: tomografía de coherencia óptica de la córnea. Epitelización completa del área adelgazada (que alcanza ahora $276 \mu \mathrm{m}$ de espesor) con desaparición casi total del quiste epitelial.

Figure A. OS: Slit-lamp biomicroscopy photograph with Cobalt Blue Filter. Fluorescein staining reveals two separate dendritic ulcers (white arrows) compromising the mid-periphery, both superonasal (at 9 and 10:30 o'clock), and superior (at 12 and 2 o'clock). Additionally, an ulcerative lesion with stromal compromise of about $3 \times 2 \mathrm{~mm}$ with thinning of more than 50\% of the total corneal thickness (white oval). Figure B. OS: optical coherence tomography of the cornea. An area of thinning (respected stromal remnant of $171 \mu \mathrm{m}$ ) with epithelial cyst on the stromal ulceration area. Figure C. OS: Slit-lamp biomicroscopy photograph with Cobalt Blue Filter. Fluorescein stain shows minimal staining on areas of epithelial dendritic ulcers, as well as almost complete healing of the stromal ulceration. Figure D. OS: optical coherence tomography of the cornea. Complete epithelialization of the thinned area (now reached thickness of $276 \mu \mathrm{m})$ and almost complete resolution of the epithelial cyst.

Figura A. OE: fotografia com lâmpada de fenda com filtro azul cobalto. A coloração com fluoresceína revela duas úlceras dendríticas (setas brancas) que comprometem a periferia média, tanto superonasal (meridiano das 9 e 10:30 horas), quanto superior (meridiano das 12 e das 14 horas). Além disso, lesão ulcerativa com comprometimento do estroma de aproximadamente de $3 \times 2 \mathrm{~mm}$ com afilamento de mais de $50 \%$ da espessura corneal (oval branco). Figura B. OE: tomografia de coerência óptica (OCT) de córnea. Observa-se uma área afinada (restos de estroma respeitados de $171 \mu \mathrm{m}$ ) com cisto epitelial sobre a área de ulceração do estroma. Figura C. OE: fotografía em lâmpada de fenda com filtro azul cobalto. A coloração com fluoresceína permite avaliar apenas a captação mínima do corante nas áreas das úlceras dendríticas epiteliais, bem como cicatrização quase completa da ulceração estromal. Figura $\boldsymbol{D}$. OE: tomografía de coerência óptica (OCT) de córnea. Epitelização completa da área afinada (que agora atinge 276 um de espessura) com quase total desaparecimento do cisto epitelial. 
Hombre de 53 años, sin antecedentes de importancia, con cuadro clínico de 30 días de evolución caracterizado por dolor tipo punzada y sensación de cuerpo extraño en ojo izquierdo (OI). Por indicación de un farmacéutico, usó colirio de dexametasona, neomicina, polimixina $\mathrm{B}$ (Wassertrol®, Wassser) 3 veces al día durante 15 días, con empeoramiento de los síntomas, motivo por el cual consultó al Centro Oftalmológico. Al examen físico, se encontraron úlceras dendríticas epiteliales en periferia superior y superonasal; además, otra úlcera de $2.5 \mathrm{~mm}$ de diámetro con compromiso estromal, con adelgazamiento en el área de la lesión y quistes epiteliales. El cuadro se consideró como afectación ocular por el virus del herpes expresada en una forma clínica de queratitis epitelial infecciosa (morfología dentrítica múltiple) y, además, queratitis estromal. Esta evolución atípica de la queratitis herpética (Figuras A y B) se relaciona, posiblemente, con el previo uso de esteroides tópicos. Se suspendió el colirio triconjugado y se inició manejo con ganciclovir gel oftálmico tópico 5 veces al día y aciclovir $2 \mathrm{~g}$ diarios vía oral, con buena respuesta evidenciada en el control al séptimo día (Figuras $\mathbf{C}$ y D).

El virus del herpes simplex (VHS) tipo I es una frecuente causa de queratitis (1), que puede comprometer cualquier capa de la córnea (epitelio, estroma o endotelio), aunque su presentación epitelial es la más común $(50 \%$ - $80 \%$ de los casos de herpes ocular) (2).

Desde hace más de 50 años se conoce la contraindicación de los corticosteroides si existe compromiso epitelial corneal por VHS, pues aumentan el riesgo de que la úlcera progrese de su forma dendrítica a una geográfica, así como la posibilidad de multifocalidad de las lesiones $(1,3-5)$ e, incluso, se incrementa la eventualidad de compromiso estromal, como en el presente caso (3-7).

Ante la sospecha de conjuntivitis infecciosa, el médico no oftalmólogo podría abordar el caso con colirios de antibióticos tópicos. Si en 48 horas no mejoran los síntomas o aparecen nuevos síntomas de alarma (fotofobia, disminución de la visión o dolor) se debe remitir al oftalmólogo. Por otra parte, el uso de esteroides tópicos debe estar restringido, ya que puede agravar la afectación ocular por el virus del herpes, como en este caso. A pesar de que los esteroides tópicos pueden ser usados para el tratamiento de diversas condiciones que se manifiestan con ojo rojo, sus indicaciones son muy precisas (8). Desafortunadamente, en nuestro medio son usados inapropiadamente tanto por médicos generales, como por los mismos pacientes siguiendo indicaciones de personal no médico (farmacéuticos), como en el presente caso. La recomendación es evaluar cuidadosamente al paciente antes de comenzar un tratamiento tópico con esteroides. Cuando se sospeche infección por VHS, los esteroides tópicos mal indicados pueden generar empeoramiento del cuadro clínico (1), como en el caso expuesto.

Para el examen del detalle de las lesiones corneales, se requieren una lámpara de hendidura y la tinción con fluoresceína, siendo improbable que un médico no oftalmólogo las pueda observar. Por ello, se debe basar en la evolución clínica y en los hallazgos macroscópicos para enfocar el diagnóstico y manejo. Entre las claves para diferenciar la conjuntivitis de la queratitis epitelial herpética están la presencia de secreción mucopurulenta en la conjuntivitis bacteriana, ausencia de fotofobia, y usualmente bilateral (ya sea bacteriana o adenoviral). En la queratitis epitelial herpética por su parte, se presenta secreción acuosa, hay fotofobia, usualmente unilateral y hay disminución de la sensibilidad corneal (1).

\section{Conflictos de interés}

Los autores declaran no tener ningún conflicto de interés.

\section{Referencias}

1. Seitz B, Heiligenhaus A. "Herpeskeratitis" Unterschiedliche Ausprägungsformen erfordern unterschiedliche Therapieansätze. Ophthalmologe. 2011;108(4): 385-97. doi: 10.1007/s00347-011-2346-5

2. Wilhelmus KR. Antiviral treatment and other therapeutic interventions for herpes simplex virus epithelial keratitis. Cochrane Database Syst Rev. 2015;1:CD002898. doi: 10.1002/14651858. CD002898.pub5.

3. Thygeson P, Hogan MJ, Kimura SJ. The unfavorable effect of topical steroid therapy on herpetic keratitis. Trans Am Ophthalmol Soc [Internet]. 1960 [citado 20 de mayo de 2019];58:245-62. Recuperado a partir de: https://www.ncbi.nlm.nih.gov/pmc/articles/ PMC1316376/

4. Patterson A, Jones BR. The management of ocular herpes. Trans Ophthalmol Soc UK [Internet]. 1967 [citado 20 de mayo de 2019];87:59-84. Recuperado a partir de: https://www.ncbi.nlm.nih.gov/pubmed/4892489

5. Patterson A. Management of ocular herpes simplex. Br J Ophthalmol. 1967;51(7):494-5. doi: 10.1136/ bjo.51.7.494

6. Roozbahani M, Hammersmith KM. Management of herpes simplex virus epithelial keratitis. Curr Opin Ophthalmol. 2018;29(4):360-4. doi: 10.1097/ ICU.0000000000000483. 
7. Prakash G, Avadhani K, Srivastava D. The three faces of herpes simplex epithelial keratitis: a steroid-induced situation. BMJ Case Rep. 2015;2015:bcr2014209197. doi: 10.1136/bcr-2014-209197

8. Galvis V, Tello A, Diaz CA. Diagnóstico del ojo rojo para el médico de atención primaria. MedUNAB [Internet]. 2008 [citado 20 de mayo de 2019];11:231-8. Recuperado a partir de https://revistas.unab.edu.co/ index.php/medunab/article/view/66. 